PSI UNISC

Recebido em: 20/02/2018

Autor para contato: rafaeldetilio.uftm@gmail.com
ISSN: $2527-1288$

Aceito em: 07/05/2018

doi: $10.17058 /$ psiunisc.v2i2.11671

\title{
Análise do Processo Discursivo das Produções Artísticas de um Movimento Estudantil
}

Análisis del Proceso Discursivo de las Producciones Artísticas de un Movimiento Estudiantil

Analysis of the Discursive Process of a Student Movement Artistic Production

\author{
Rafael De Tilio \\ ORCID: http://orcid.org/0000-0002-4240-9707 \\ Universidade Federal do Triângulo Mineiro - Minas Gerais/Brasil
}

\section{Resumo}

Discursos produzidos pelos movimentos estudantis universitários circunscrevem reivindicações políticas, éticas e estéticas não limitadas às demandas da educação. Essa pesquisa teve como objetivo compreender o processo discursivo (o estabelecimento de efeitos de sentidos) das produções artísticas de membros de um movimento estudantil numa universidade pública em 2014. O arquivo de análise possui 482 imagens (desenhadas no espaço físico da universidade) fotografadas e analisadas a partir da Análise de Discurso de Pêcheux. A análise visou: (1) a constituição do objeto discursivo, e (2) a elucidação do processo discursivo, sendo este enfatizado. Os discursos apontam para a constituição de um efeito de sentido de universalização ( $o$ movimento estudantil composto por todos os universitários) das reivindicações para redistribuir as relações de poder naquele cenário. Para tanto, aqueles discursos estão apoiados em referenciais (interdiscursivos) disponíveis na cultura considerada ilustrada e nãoalienada e na ideologia, fomentando a luta política como estratégias de transformação social daquele/naquele contexto.

Palavras-chave: Arte; Discurso; Políticas de educação superior; Linguagem.

\section{Resumen}

Discursos producidos por los movimientos estudiantiles universitarios circunscriben reivindicaciones políticas, éticas y estéticas no limitadas a las demandas de la educación. Esta investigación tuvo como objetivo comprender el proceso discursivo (el establecimiento de efectos de sentidos) de las producciones artísticas de miembros de un movimiento estudiantil en una universidad pública en 2014. El archivo de análisis posee 482 imágenes (dibujadas en el espacio físico de la universidad) fotografiadas y analizadas a partir del Análisis de Discurso de Pêcheux. El análisis dirigido a: (1) la constitución del objeto discursivo, y (2) la elucidación del proceso discursivo, que se enfatiza. Los discursos apuntan a la constitución de un efecto de sentido de universalización (el movimiento estudiantil compuesto por todos los universitarios) de las reivindicaciones para redistribuir las relaciones de poder en aquel escenario. Para ello, esos discursos están apoyados en referenciales (interdiscursivos) disponibles en la cultura considerada ilustrada y no alienada y en la ideología, fomentando la lucha política como estrategias de transformación social de aquel / en ese contexto.

Palabras clave: Arte; El habla; Políticas de educación superior; Idioma.

\section{Abstract}

The discourses produced by university student are circumscribing for political, ethical, and aesthetic claims, but they are not limited to educational demands. This research aimed to understand the student movement artistic productions speeches (senses effects) in a public university in 2014. 482 images 
(drawn in that university) were photographed and analyzed from Pêcheux Analysis of Discourse. Thus, this corpus was treated aiming at the constitution of the discursive object and the discursive process. The discourses reflects (despite the diversities actors gathered in the student movement) an attempt to universalize the struggle to promote innovates power relations in that scenario. Besides, these discourses are influenced by interdiscourse and ideology, supported by (interdiscursive) references available in the illustrated culture (literature, music, and art), fostering the establishment and maintenance of militancy and political struggle as strategies of social transformation in that context.

Keywords: Art; Speech; Higher education policy; Language.

\section{Introdução}

A arte pode ser compreendida como a tradução, mediante adequação ou questionamento, da cultura, tradição e identidade de uma sociedade. Isso estabelece uma relação entre a produção cultural de um grupo social e o meio (sociedade) em que se encontra (Gianvecchio, 2008). Ainda para Gianvecchio (2008), em diversos momentos na história, a arte assumiu a função de retratar os acontecimentos da realidade e refletir sobre eles. Nessa trajetória, podemos ver exemplos de diversificadas formas de violências sofridas pela sociedade, tais como violações no corpo, na escrita, no pensamento e na organização social dentre outros.

Mas o que define uma obra de arte? Para Benjamin (2011), ela pode ser definida como um objeto resultado da criação humana que expressa um conceito ou representação de elevado valor simbólico e social. Mais precisamente, para Coli (2015), o que considerado uma obra de arte não seria definida por suas qualidades técnicas e/ou materiais, mas sim pelo campo das convicções, ou seja, pela crença de que aquele objeto representa aspectos considerados relevantes e significativos para um agrupamento social num momento histórico específico.

Para Moscheta (2014), é arriscado e complexo definir a arte e mais ainda a arte pósmoderna, pois uma das marcas principais desse movimento artístico e suas produções é a recusa às explicações e definições totalizantes. A potência dessa arte não se restringe apenas ao que é retratado (causa), mas se relaciona principalmente ao que é produzido (efeitos), ou seja, o estranhamento, o desconforto e a necessidade de refletir sobre ela para poder apreciá-la. Ainda para Coli (2015), a função precípua da arte é promover o incômodo visando à produção da reflexão (a transformação da experiência do observador), e não sua pacificação. É assim que ela se desloca da mera representação da realidade para a intencionalidade em provocar efeitos subversivos nos espectadores de forma que não é apenas consumida como apreciação estética, mas imbuída da pretensão em estabelecer relações éticas e/ou políticas transformadoras (Benjamin, 2014).

Assim, para Coli (2015), desde a modernidade, a arte (e de maneira mais evidente na arte pós-moderna) o campo da estética não pode ser pensado independentemente do ético e do político (relações de poder): se a arte não pode desconsiderar seus efeitos nos desdobramentos da estetização do político (adequação ou questionamento do status quo), por outro lado a recusa da ética e da política da representação artística (quando adequada à realidade representada) é também um fato político. Portanto, as diversas modalidades de arte não podem ser qualificadas a partir dos critérios da adequação ao que se representa, mas sim a partir dos impactos e consequências políticas que gera (Gianvecchio, 2008).

Para Giordani (2011), ao considerar a arte como uma das manifestações da linguagem pode-se entendê-la a partir de sua função na sociedade, pois ela não se limita a ser um mero meio de comunicação, mas sim seria reflexo da própria sociedade e de seus modos de funcionamento. A arte configuraria uma 
construção simbólica da realidade de forma que reflete e constitui a percepção que os atores sociais possuem do mundo e como se relacionam com ele. Dessa forma as diversas manifestações artísticas seriam instrumentos de conhecimentos, comunicações e expressões dos plurais atores sociais (Giordani, 2011).

Ainda para Giordani (2011) a principal função da arte pós-moderna é ser uma política contestatória das normalizações, isto é, ser instrumento de crítica e questionamento; consequentemente, disso decorre numa impossibilidade de neutralidade na transmissão da mensagem, e o objetivo artístico sempre traduziria a posição (social e política) do(s) seu(s) autor(es). Portanto, as diversas manifestações artísticas travam disputas de sentidos e de ideologias (visões de mundo) e relações de poder e, assim, longe de serem representações da realidade, são práticas sociais.

Assim, o potencial de poder da arte pósmoderna não estaria no objeto resultado produzido, mas sim na legitimidade que lhe é conferida pelos que a produzem e pelos que a recebem (o já referido campo das convicções), e a arte pode ser entendida como um discurso (definido como efeitos de sentidos - Pêcheux, 2009) e, portanto, como um mecanismo de poder de constituição da significação da realidade.

O discurso, portanto, produz sentidos de uma determinada maneira e circunscreve um conjunto de relações possíveis com e entre eles. Nesse sentido, na medida em que o discurso regula e dá forma as possibilidades de viver (e de relações de poder), ele sustenta as práticas sociais por meio das quais o poder opera. (Moscheta, 2014). A inovação da ideia de (relações de) poder em Foucault (2010), ao contrário dos sociólogos clássicos, está em descrevê-lo não apenas em seus aspectos repressivos (negatividade do poder), mas também em seus aspectos organizativos que estruturam e organizam as relações entre os indivíduos (positividade do poder) - o que não significa que as relações de poder sejam igualitárias ou equânimes. Para o autor, o poder não opera somente nas proibições, cerceamentos e obrigações, mas funciona, sobretudo, nas incitações, na criação de desejos, expectativas, antecipações e projetos que cooperam na criação de um modo esperado de viver.

Diante do exposto, as produções (desenhos, textos, grafismos etc.), doravante denominadas de produções artísticas, de autoria do movimento estudantil de uma universidade pública realizadas em 2014 nas suas paredes, portas e vidros podem ser compreendidas como discursos (efeitos de sentidos) tal como definido por Pêcheux (2009). Mais precisamente, as produções artísticas naquele espaço que envolve objetos reais e simbólicos produzidos pela e na ação humana (Costa, 2014) podem ser conceituadas de discursos por produzirem (efeitos de) sentidos dentre os interlocutores daquela universidade e, assim, para sua plena compreensão necessitam ser situados em relação as suas filiações discursivas e ideológicas (Pêcheux, 2009).

Essa pesquisa se justifica tanto pela necessidade de contextualizar a produção de sentidos como realizar o registro histórico das estratégias de reivindicação do movimento estudantil de uma universidade pública, o que pode contribuir para com a discussão e acerca das formas de reivindicação e participação política nas universidades públicas. Assim, o presente artigo tem como objetivo compreender o processo discursivo (o estabelecimento de efeitos de sentidos) das produções artísticas de um movimento estudantil de uma universidade pública em 2014.

\section{Aspectos metodológicos: constituição do corpus e procedimentos de análise}

Trata-se de uma pesquisa descritiva e exploratória, de caráter qualitativo, de corte transversal e com utilização de imagens das produções artísticas produzidas em 2014 por um movimento estudantil de universidade pública. A pesquisa qualitativa pretende compreender aspectos da realidade e da dinâmica das relações sociais a partir do universo dos significados, crenças, valores, 
motivos e atitudes que permeiam relações, processos e fenômenos (Richardson, 2015).

Em relação à constituição do corpus por tratar-se de produções artísticas materializadas no formato de imagens, textos (trechos de músicas e de livros e palavras de ordem) e grafismos pintados no espaço de numa universidade federal pelo movimento estudantil em 2014 todas as imagens produzidas foram fotografadas (em quatro ocasiões durante o mês de maio de 2015), constituindo um vasto arquivo de imagens de referência.

Para isso foi utilizada uma câmera fotográfica do aparelho Ipod5 de uso pessoal do pesquisador. No total foram registradas/fotografadas 496 imagens que foram arquivadas no Dropbox (um dispositivo de armazenamento e partilha de arquivos online; o álbum dessas imagens está publicamente acessível e pode ser visualizado por qualquer pessoa a qualquer momento em https://www.dropbox.com/sh/cwq15xu561b76 wm/AAAbuTrSPhgUIIsHMXf5jQtAa?dl=0) e também em CD-ROOM.

É significativo destacar que, desde o momento da sua produção, parte dessas produções artísticas foi e tem sido apagada tanto por intervenções dos funcionários da universidade como pela ação do tempo, enquanto outras surgiram produzidas por autores desconhecidos e após o ano de 2014. Portanto, o corpus de imagens (arquivo de referência) utilizado nesta investigação não é, necessariamente, $\mathrm{o}$ original $-\mathrm{e}$ tampouco necessitaria ser, haja vista que o propósito da Análise de Discurso é mostrar como um discurso funciona produzindo (efeitos de) sentidos, o que não condiz com a suposição de uma verdade imanente a ser desvelada, porém sim à constituição de um regime de verossimilhança possível (Orlandi, 2013).

$\mathrm{O}$ arquivo de referência foi analisado segundo os pressupostos da Análise do Discurso (AD) proposto por Pêcheux (2009). Assim, parte-se do pressuposto de que o discurso é o lugar no qual ocorre a relação entre a linguagem e a Ideologia. Os discursos não são conceituados como conteúdos neutros delimitados a priori nem como elementos de transmissão de informações; na AD o discurso é o espaço no qual decorrem processos de interpelação, identificação e posicionamento dos sujeitos - ou seja, são processos de subjetivação, argumentação, produções de sentidos e construções sociais (Orlandi, 2013).

Segundo Pêcheux (2009) e Orlandi (2013), podem ser distinguidos duas formas de esquecimentos que estruturam e possibilitam $\mathrm{o}(\mathrm{s})$ (efeitos de sentidos dos e nos) discurso(s). O Esquecimento Número 1 refere-se à ilusão ideológica: a crença de que o sujeito é a origem do que é dito quando, na realidade, o que é dito é resultado dos posicionamentos históricos, sociais, ideológicos e situacionais dos falantes, isto é, em outras palavras, o discurso é resultante da interpelação ideológica promovida pela linguagem (Pêcheux, 2009). Não há, portanto, sujeito sem (interpelação da) ideologia e não há ideologia sem sujeito.

Por sua vez, o Esquecimento Número 2 faz menção à suposição de que quando determinado discurso é produzido há ilusão de que a única maneira de exprimi-lo é por meio das exatas palavras que foram utilizadas, não havendo outras possibilidades. Desta maneira, para a $\mathrm{AD}$ o modo de dizer também significa. $\mathrm{O}$ Esquecimento Número 2 diz respeito às relações entre fala e interdiscurso (o que foi dito e o que não foi dito [não-dito]); em suma, outras maneiras de dizer, os não-ditos e os silenciamentos, poderiam fazer parte do que foi dito mas não o foram devido às Formações Discursivas (situacionalidades delimitadas pela ideologia que interpela o sujeito) as quais pertencem os falantes (Pêcheux, 2009).

Para a $\mathrm{AD}$, esses dois esquecimentos são inconscientes, e a função do analista do discurso é compreender de que maneira eles afetam produção de sentidos dos interlocutores (Orlandi, 2013). Assim, em termos de procedimentos metodológicos de análise a $\mathrm{AD}$ parte de um material linguístico qualquer (o corpus, no caso, o arquivo de referência) e o transforma em objeto discursivo (desvelamento das relações do corpus com o interdiscurso, 
desfazendo o funcionamento do Esquecimento Número 2) e, depois, o transpõe para o estatuto de processo discursivo (desvelando as formações ideológicas específicas do contexto de produção do objeto discursivo, revelando os esquemas de funcionamento do Esquecimento Número 1) (Pêcheux, 2009; Orlandi, 2013).

Por isso, na $\mathrm{AD}$ os procedimentos de análise dos dados são indissociáveis do referencial teórico. Para Orlandi (2013) a AD não trata da língua ou da gramática, embora essas lhe interessem: ela trata do discurso (como, por quem e em quais condições os sentidos entre interlocutores são produzidos e significam). Procura-se, assim, compreender a linguagem produzindo sentidos, enquanto campo simbólico e constitutivo do homem e da sua história. O discurso é um objeto sóciohistórico, por isso de elevado interesse para a Psicologia Social.

\section{Resultados e discussão}

Em primeiro lugar serão relatados exemplos das produções artísticas produzidas por integrantes do (denominado) movimento estudantil em 2014, no espaço de uma universidade federal (Universidade Federal do Triângulo Mineiro) e suas relações com o interdiscurso; depois serão abordadas as condições ideológicas que permitem compreender tal produção naquele cenário e contexto específicos enfatizando o processo discursivo.

\section{A produção artística no espaço daquela universidade - o objeto discursivo}

É importante precisar que as produções artísticas daquele movimento estudantil naquele espaço fizeram parte de uma série de estratégias e instrumentos que pretendiam a visibilidade das suas demandas. A demanda prioritária daquele movimento estudantil universitário era a efetivação da qualidade da educação no ensino superior (incluindo $\mathbf{o}$ aumento da qualidade do processo de ensino e aprendizagem, a transparência orçamentária, a melhora das condições físicas da universidade e da distribuição de auxílios e benefícios sociais destinados aos discentes), e a plataforma de luta era pressionar a reitoria local para aumentar do número de vagas de docentes efetivos daquela universidade.

Todavia, segundo Mesquita (2003), o movimento estudantil (incluindo o universitário) é, antes de tudo, um movimento plural que não se restringe nem às demandas específicas concernentes às políticas educacionais nem às organizações discentes formais, congregando demandas e atores de outros movimentos sociais que porventura circulam naquele espaço universitário. Assim, mesmo que se pretendesse universalizante (ser reconhecido como o movimento estudantil), ele estava composto por diversos segmentos (movimentos estudantis e sociais) ao mesmo tempo em que não abrangia e representava todos os discentes daquela universidade. Todavia, segundo Orlandi (2013), um dos principais efeitos do discurso-universal é o de pretender fazer-se reconhecido pela ilusão de não haver dissonâncias e questionamentos internos na tentativa de estabelecer relações de força para com seus externos/opositores.

Em outras palavras, as produções artísticas daquele espaço universitário não estão compostas somente pelas demandas acadêmicas e educacionais dos discentes (ou seja, um interesse voltado unicamente para as políticas universitárias e educacionais), mas incluía demandas diversas que perpassam as vivências dos estudantes (num exemplo do funcionamento do interdiscurso), tais como discursos de minorias étnico-raciais (nominalmente, as dos afrodescendentes e de refugiados) e de gênero (mulheres e trans).

Portanto, é significativo compreender quais discursos circulavam naquela diversidade, e isso pode ser realizado por meio da escansão das produções artísticas produzidas por integrantes do movimento estudantil naquele momento - cuja totalidade pode ser visualizada no arquivo online do Dropbox anteriormente citado. A opção por não enfatizar uma imagem ou categoria de imagens específicas, mas sim seu conjunto, se justifica 
por ser ênfase, nesta pesquisa, a compreensão do processo discursivo.

As produções artísticas representavam um leque diverso de sentidos não necessariamente relacionados ao campo (discursivo) específico da educação, tais como imagens e frases de personalidades políticas de resistência e de orientação doutrinária de esquerda (exemplos: José Martí, Mandela, Marx, Engels, Mariguella, Che Guevara, Pepe Mujica, José Paulo Neto, Lênin, Luís Carlos Prestes, Salvador Allende, Antônio Gramsci, Olga Binário, István Mészarós), de acadêmicos e escritores brasileiros (exemplos: Sérgio Buarque de Hollanda, Paulo Freire, Moacir Gadotti, Mauro Iasi, Carlos Latuff, Aziz Ab'Saber, Florestan Frenandes, Caio Prado da Silva Junior) e não brasileiros (Nietzsche, Guatarri, Foucault, Voltaire, Dostoiévski, Sartre, Hobsbawn, Hanna Arendt, Descartes, Martin Lutherking Saussure, Tolstói). As produções artísticas também contemplavam expressões de grupos políticos específicos como negros e afrodescendentes (exemplos: Panteras Negras, Abdias Nascimento, Malcoln $\mathrm{X})$ e feministas e/ou trans (Frida Kahlo, Pagu).

Além disso, as produções artísticas também manifestam temas amplos mesclando referências nacionais e internacionais no âmbito da cultura e dos direitos sociais (exemplos são as palavras de ordem a favor da cultura popular e contra o elitismo evidenciando a desigualdade social), da literatura (Carolina Maria de Jesus, Guimarães Rosa, João Cabral de Neto, Fernando Pessoa, Clarice Lispector, Machado de Assis, Thiago de Mello, Paulo Leminsk, Vinícius de Moraes, Bertold Brechet, Mário Benedetti, Neusa Doretto, Cora Coralina, Pablo Neruda, Antonin Artaud, Maria Firmina dos Reis, Zé Geraldo, José Saramago, Manoel de Barros, Virgínia Woolf, Carlos Drummond de Andrade, Samuel Bekett, Florbela Espanca, Manuel Bandeira, Ágatha Cristie, Franz Kafka, Edgar Allan Poe) e da música (Cazuza, Cássia Eller, Nação Zumbi, Mano Brown, Bob Marley, Chico Science, Adoniran Barbosa, Chico Buarque, Clara Nunes, Elis Regina, Cartola, Planet Hemp, Belchior, Caetano Veloso, Macaco
Bong, Paulo Vanglorini, Criolo, Gabriel, O Pensador, Tom Zé, Lulu Santos, Raul Seixas, Nando Reis, Dorival Caymmi, Oriente, Gonzaguinha, Milton Nascimento, João Nogueira, Sabotage, Pink Floyd, Candeia, Novos Baianos, Maria Rita). Também há referências aos desenhos animados (Simpons, Batman, Pink e Cérebro, Watchman), pintores (Pablo Picasso e Tarsila do Amaral) e outras produções que são apenas grafismos e/ou desenhos (flores, pés, árvores, astronauta, desenhos geométricos, portas pintadas).

Parte dessa variedade de produções artísticas deve ser compreendida como representações do ideário político daquele movimento estudantil que pretende se reafirmar pelo conteúdo que estão propostos a encampar, essencialmente os relacionados ao questionamento da ordem vigente na universidade e tocante à qualidade do ensino; mas, a própria diversidade de representações e demandas denuncia a impossibilidade da universalização e revela as relações interdiscusivas daquelas produções.

Para Orlandi (2013), o interdiscurso tem relação com a memória discursiva (o já-dito) de uma sociedade, grupo ou espaço social. Para a autora, a memória faz parte do discurso e dele participa como interdiscurso (o que está nos entremeios do discurso, quase nunca evidente, mas importante para o estabelecimento dos sentidos). Conceitualmente, o interdiscurso ou memória discursiva são definidos como o conjunto de significados e significações que antecipam e possibilitam os dizeres do sujeito e dos interlocutores (Pêcheux, 2009); portanto, o interdiscurso é algo que já foi dito (podendo ser redito ou não) numa sociedade e que causa efeito no que se está sendo dito, revelando seus compromissos políticos e ideológicos (Orlandi, 2013).

Exemplo disso são as produções artísticas daquele contexto que foram já-ditas em outros contextos, mas que causam efeitos de sentidos também naquele espaço universitário. Segundo a AD, o interdiscurso/memória discursiva possibilitam o resgate de uma ampla gama de sentidos disponíveis aos 
interlocutores, mas cuja escolha não se dá nem por acaso nem por domínio consciente das possibilidades, mas sim ocorre mediante o disponibilizado pela Formação Ideológica (a série de representações e sentidos considerados verdadeiros e estruturantes para uma sociedade e/ou grupo) e pela Formação Discursiva (o que pode e deve ser dito) as quais os falantes estão filiados (Orlandi, 2013; Pêcheux, 2009).

A partir disso, é possível considerar que as escolhas (das produções artísticas efetivadas naquele espaço por aquela população diversificada) respondem às condições discursivas específicas que determinam efeitos de sentidos específicos (questionamentos; manutenção de tensões nas relações de poder; representação das suas crenças e expectativas, dentre outros), não sendo resultantes de aleatoriedades. E é dessa maneira que o interdiscurso se relaciona com o Esquecimento Número 2 (ilusão que o único modo de dizer/significar algo é justamente pelo modo pelo qual foi feito, quando na verdade o que e como se diz/significa algo responde às filiações discursivas e ideológicas).

Mesmo que não universal (o movimento estudantil) essas práticas de produções artísticas como estratégia política se gesta e se fortalece como um modo inovador de fazer política (relações de poder) naquele contexto burocratizado e hierarquizado - cujas paredes, destaca-se, eram totalmente brancas ou vazias), resultando em novos tensionamentos, questionamento e lutas. Para Rancière (2009), política e arte têm uma origem comum. A política, para o autor, é essencialmente estética, ou seja, está fundada sobre o mundo sensível, assim como a expressão artística. Por isso, um regime político democrático como o desejado por aquele movimento estudantil naquele contexto só pode ser consolidado caso haja efetiva multiplicidade de manifestações dentro da comunidade (Volanin, s.d.) - por isso a importância da diversidade das produções artísticas como forma de denúncia e de produção de sentidos outros dos problemas sociais.
Não há, portanto, como pensar a sociedade sem manifestações adversas ao status quo ante já que elas surgem da insatisfação por parte de determinada classe ou grupo social e esbarram em interesses de classes antagônicas que tentam abafar os desejos de reformas. Por isso, os efeitos de sentido produzidos pelos discursos inerentes às produções artísticas daquele movimento estudantil também geraram resistências: num primeiro momento aquelas produções artísticas foram consideradas crimes (depredação do espaço público) pelos gestores institucionais o que culminou numa denúncia, porém rejeitada, da reitoria local ao Ministério Público Federal contra os líderes do movimento estudantil (Movimento Estudantil, 2016) - e, mais recentemente, elas tem sido progressiva e furtivamente cobertas por tinta branca pelos gestores universitários.

\section{O contexto local e as condições ideológicas - o processo discursivo}

Para Lopes (2003), na década de 1950 a elite da sociedade na qual a universidade em apreço se situa estava descontente com a política tributária estadual, e considerando os impactos negativos disso o governador na época intencionou conhecer quais eram os anseios da população naquele momento. Assim, em 1953, reuniram-se o governador e as principais lideranças políticas municipais que revelaram seus anseios pela criação de um curso de medicina que poderia auxiliar no desenvolvimento da cidade. Dessa forma, foram concretizadas ações visando à criação de uma faculdade de medicina (Lopes, 2015).

A partir disso, pode-se perceber a relevância dos aspectos políticos e econômicos na constituição histórica de criação daquela universidade, já que os médicos estavam alinhados com as principais lideranças dos segmentos políticos e educacionais municipais. A forte presença da categoria profissional dos médicos e suas concepções sobre política (elitismo), educação (pragmatismo) e saúde (curativismo biológico) são marcas e resquícios interdiscursivos importantes na identidade institucional daquela universidade. 
No contexto nacional entre as décadas de 1960 e 2000, houve um aumento significativo do número de matrículas no ensino superior, especialmente no âmbito das instituições privadas. Nesse cenário, foi proposto dentre outras políticas públicas de educação o Programa de Apoio aos Planos de Reestruturação e Expansão das Universidades Públicas Federais (REUNI), cujo propósito era:

Dotar as Universidades Federais das condições necessárias para ampliação do acesso e permanência na educação superior, e também como forma de congregar esforços para a consolidação de uma política nacional de expansão da educação superior pública brasileira (Brasil, 2007, p.10).

Naquele contexto específico, em 2007, aquela instituição de ensino superior (que tinha cursos nas áreas de saúde) foi transformada em universidade federal e passou a receber cursos nas áreas de humanidades, licenciaturas e engenharias (UFTM, 2007). A universidade passou por uma expansão significativa, triplicando o número de cursos de graduação e quadriplicando a oferta de vagas discentes entre 2006 e 2010.

Entretanto, o crescimento de cursos de matrículas daquela universidade não foi acompanhado da proporcional implementação de condições adequadas para esse objetivo, tendo em vista que a quantidade de docentes, servidores técnicos administrativos e espaço físico não tiveram expansão em igual escala. Além disso, também não houve adequada expansão dos espaços físicos que proporcionassem aos estudantes uma formação acadêmica e cidadã de qualidade (UFTM, 2007; 2012). Disso decorreu, segundo aquele movimento estudantil (2014), uma precarização das condições de trabalho e de ensino-aprendizagem (materializado na falta de professores, insuficiência e ineficiência de políticas de permanência estudantil, de infraestrutura adequada para consolidação dos cursos abertos pelo REUNI, na falta de transparência orçamentária etc.) que prejudicavam não apenas os discentes, mas toda a comunidade acadêmica.

Foi diante desta realidade de expansão descontrolada das universidades federais que foi reorganizado o movimento estudantil daquela universidade. Aquele movimento estudantil teve como propósito principal questionar a atuação dos gestores institucionais diante daquelas circunstâncias prejudiciais. Naquele cenário, foi fundamental o papel do movimento estudantil tanto visando à conscientização política (sobre a necessária qualidade da educação) como a premente atuação para o enfrentamento das adversidades (visando o direito ao ensino público de qualidade e socialmente orientado).

Naquele momento, as crescentes insatisfações do movimento estudantil foram motivadas pelas respostas (paliativas) por parte da reitoria local apresentadas para suas demandas, culminando em fevereiro de 2014 em ações políticas não usuais naquele contexto, tais como a ocupação física (os integrantes do movimento estudantil em esquema de revezamento passaram a dormir nas dependências da universidade) e simbólica (as produções artísticas) do prédio central daquela universidade, além do panelaço (utilização de panelas e outros instrumentos para produzir barulho visando impedir a realização das aulas) e do cadeiraço (empilhamento de cadeiras para impedir a circulação no espaço físico da universidade).

Para Hamann, Tedesco e MaracciCardoso e Viscardi (2013) esses atos de protesto político pretendem uma interpelação real e simbólica do espaço (físico, social e afetivo) que promova uma nova significação e apropriação do mesmo, permitindo novas identidades e relações sociais. Exemplo disso é que o espaço físico da universidade, antes todo branco tal como um hospital (bem ao gosto da história e da reitoria local), passou a ser colorido pelas produções artísticas; também houve alterações na circulação e permanência das pessoas naquele cenário, haja vista que os estudantes que ali ficavam apenas para frequentar aulas (decorrente das condições 
arquitetônicas e urbanísticas daquela universidade) passaram a habitar (jogar baralho, tocar violão, promover rodas de debates nos corredores etc.) efetivamente a universidade. Em suma, o movimento estudantil passou a reivindicar para si a universidade, o que implicava numa redistribuição das relações de poder.

Assim, ao questionarem, exigirem e partirem para uma ação concreta para objetivar suas demandas, os estudantes estabeleceram práticas e relações de poder não usuais (em outros termos, outros discursos) naquele espaço, questionando o status quo ante (Foucault, 2010). De um não-lugar (para os estudantes), a proposta do movimento estudantil era tornar aquele ambiente universitário rico em presença e em debates.

Ristoff (2014) evidencia que as políticas públicas mais recentes de inclusão dos grupos historicamente excluídos do ensino superior começaram a alterar significativamente o perfil típico do estudante de graduação das universidades públicas. Dessa forma, infere-se uma transformação do tecido social e, por extensão, dos discursos que compunham aquela (e outras) universidade(s). Para a AD, portanto, o resgate e a explicitação da história (que compreende o interdiscurso, a memória discursiva, as formações discursivas e a ideologia) e as condições históricas de produção são fundamentais para a compreensão dos fenômenos discursivos que, conforme já apresentado, são atingidos pelos esquecimentos próprios ao funcionamento da linguagem (Pêcheux, 2009).

Compreender a interpelação ideológica (isto é, as condições materiais de produção dos discursos) é fundamental para desvelar as próprias condições pelas quais os discursos podem ser formulados - essa é outra maneira de definir a etapa de análise do processo discursivo (Orlandi, 2013). Por Ideologia, segundo Pêcheux (2009) e Orlandi (2013), devem ser compreendidos os processos de funcionamento do discurso (nominalmente $o$ Esquecimento Número 1) que apagam (e impede o acesso consciente a) os traços da sua própria constituição, estabelecendo a sensação de que o mundo (as relações, os sentidos) são daquela maneira porque é natural e óbvio que assim sejam.

Portanto, como não há discurso sem ideologia (conjunto de representações), pois qualquer discurso é interpelado pelo processo ideológico (Ideologia), o que determina o que pode ou não ser dito por determinado sujeito (individual ou coletivo) em determinado contexto e em determinado momento histórico, é o que se denomina de Formação Ideológica (Orlandi, 2013).

A Formação Ideológica está articulada ao funcionamento do Esquecimento Número 1 proposto por Pêcheux (2009) justamente por referir-se à ilusão ideológica, ou seja, a crença de que o sujeito (individual ou coletivo) é o único e exato ponto de partida e de formulação daquilo que é dito, quando na verdade ela (a Formação Ideológica) remete a formações discursivas que oferecem possibilidades específicas de dizer e de posicionamentos delimitados a um e num discurso.

Diante dessa ilusão de autoria, a produção artística do movimento estudantil naquele espaço não deve ser compreendida como uma produção separada ou autônoma do contexto social mais amplo (as lutas políticas e sociais), mas sim como uma manifestação das diferentes formações ideológicas e do interdiscurso diante de uma história local (que não se separa da nacional), já que faz uso de referências dispersas que expressam determinadas ideologias - a pluralidade das demandas e das formas de posicionamento político. Isso apenas reforça a dependência das demandas daquele movimento estudantil ao contexto social e histórico.

Dessa forma, as produções artísticas do movimento estudantil daquela universidade devem ser compreendidas como um dos processos possíveis de manifestação da Ideologia e, mais precisamente, como uma Formação Ideológica específica que atribui elevado valor a educação como instrumento de bem-viver e de conhecimento crítico da 
realidade. Por isso, é necessário compreender como a organização social, o tempo e a própria história foi significada durante o processo de formação daquela universidade até culminar com os processos reativos (produções artísticas) historicamente localizados (2014) ao status quo ante.

Pensar o funcionamento do discurso e, consequentemente, a história e a ideologia como materialidades (por exemplo, as produções artísticas) é igualmente pressupor que ambas não são transparentes, nem naturais, nem neutras, sendo a partir delas que se pode notar o funcionamento da ideologia no discurso (Orlandi, 2013).

\section{Considerações finais}

A Análise do Discurso das produções artísticas daquela universidade federal está intimamente ligada ao contexto sócio histórico da universidade e do movimento estudantil. Por meio do material mobilizado (corpus) e do estudo da história da universidade pode-se refletir a transformação do histórico da universidade e quais elementos o compõem na atualidade, perpassados por discursos e ideologias que agregam a militância e a luta política visando à reorganização das políticas públicas em educação. Dessa forma, o objetivo dessa pesquisa (compreender o processo discursivo dos efeitos de sentidos [os discursos] das produções artísticas) foi cumprido.

É importante ressaltar que assim como tratado ao longo do texto, as produções do movimento estudantil foram consideradas como manifestações artísticas, e mais precisamente como modalidades da arte pósmoderna - mais importam seus efeitos do que seus materiais. Sendo assim, é de interesse dos analistas do discurso não reproduzirem sentidos cristalizados sobre essas produções. Elas existem dessa forma porque recusam explicações e definições totalizantes, servindo à apreciação estética também como ética e política. Essa postura pretende produzir não conclusões e sedimentações, mas prioritariamente compreender de que modos os sentidos se produzem. Dessa forma, aqui foi apresentado apenas uma das possíveis perspectivas de análise desse amplo cenário. A Análise do Discurso também permite desnivelar possíveis sentidos e, assim, afirmar apenas um modo de interpretação e dizer (considerados mais verdadeiros ou corretos) seria um equívoco.

Tecendo uma relação com a política atual brasileira, nos últimos meses de 2016 ocorreram ocupações de escolas públicas por estudantes secundaristas. Os estudantes estão ocupando seus locais de estudo como forma de protesto diante do sucateamento da educação pública de qualidade. Ademais, no primeiro semestre de 2017 foram amplamente noticiados questionamentos de alguns segmentos populacionais (tradicionais) junto à algumas exposições e museus que pretendiam problematizar questões de sexualidade e gênero, sendo por eles considerados ultrajantes. O que fica da observação da militância nestes diferentes espaços é que a juventude tenta romper com estruturas dominadoras e torna-se, das mais diferentes formas possíveis e com suas mais variadas práticas, um ator coletivo que protagoniza desejos de transformação social.

Diante do exposto, pode-se considerar que a produção artística questionadora dos padrões tradicionais pode possibilitar discutir formas de reivindicação e participação políticas não reconhecidas pelos discursos oficiais, destacando o papel deste e de outros movimentos sociais que militam dentro (e fora) das universidades públicas.

\section{Referências}

Benjamin, W. (2011). A obra de arte na época de sua reprodutibilidade técnica. In T. Adorno, Teoria de cultura de massa (pp.221-254). São Paulo: Paz e Terra.

\author{
Brasil (2007). REUNI - Reestruturação e \\ Expansão das Universidades Federais. \\ Brasília. Recuperado de
}


http://portal.mec.gov.br/sesu/arquivos/pdf/d iretrizesreuni.pdf.

Coli, J. (2015). O que é Arte. São Paulo: Brasiliense.

Costa, F. R. (2014). O conceito de espaço em Milton Santos e David Harvey. Revista Percurso - NEMO, 6(1), 63-79.

Foucault, M. (2010). Microfísica do poder. Rio de Janeiro: Graal.

Gianvecchio, A. (2008). A representação da violência nas artes visuais [artigo completo]. In Anais do XIX Encontro de História: poder, violência e exclusão. São Paulo: ANPUH/SP - USP. 2008.

Recuperado de http://www.anpuhsp.org.br/sp/downloads/C D\%20XIX/PDF/Autores\%20e\%20Artigos/ Adriana\%20Gianvecchio.pdf.

Giordani, L. R. (2011). As relações de poder exercidas através do discurso. Recuperado de

http://http://www.bocc.ubi.pt/pag/giordanirosselane-as-relacoes-de-poder-exercidasatraves-do-discurso.pdf.

Hamann, C.; Tedesco, P. C.; MaracciCardoso, G. J., \& Viscardi, F. (2013). Movimentos de ocupação urbana: uma integração teórica através do conceito de happening. Diálogo, 23, 19-33.

Lopes, M. A. B. (2003). Projeto memória da FMTM. Texto não publicado. Uberaba.

Lopes, G. S. M. A criação da Faculdade de Medicina do Triângulo Mineiro em Uberaba - MG: De instituição privada à instituição isolada de ensino superior (1953-1960) [palestra]. In Encontro de História da Educação da região CentroOeste. Catalão/GO.

Mesquita, R. M. (2003). Movimento estudantil brasileiro: práticas militantes na ótica dos novos movimentos sociais. Revista Crítica de Ciências Sociais, 66, 117-149.

Moscheta, M. (2014). A pós-modernidade e o contexto para a emergência do discurso construcionista social (pp.23-47). In C. Guanes-Lorenzi, M. Moscheta, C. M.
Corradi-Webster, \& L. V. Souza (Orgs.), Construcionismo Social: discurso, prática e produção de conhecimento. Rio de Janeiro: Instituto Noss.

Movimento Estudantil. Nota De

Esclarecimento de 22/04/2014. (2014).

Recuperado de

https://www.facebook.com/movimentoestu dantiluftm/photos/a.1464312913780558.10 73741828.1464196777125505/1467970353 414814/?type $=3 \&$ theater.

Orlandi, E. P. (2013). Análise do Discurso: Princípios e Procedimentos. Campinas: Pontes

Pêcheux, M. (2009). Semântica e Discurso. Campinas: Editora da UNICAMP

Rancière, J. (2009). A associação entre arte e política segundo o filósofo Jacques Rancière (entrevista a Gabriela Longman e Diego Viana). Revista Cult $n^{a} 139$.

Recuperado de http://revistacult.uol.com.br/home/2010/03/ entrevista-jacques-ranciere/.

Ristoff, D. (2014). O novo perfil do campus brasileiro: uma análise do perfil socioeconômico do estudante de graduação. Avaliação: Revista da Avaliação da Educação Superior (Campinas), 19(3), 723-747.

UFTM. Universidade Federal do Triângulo Mineiro. (2007). Histórico. Recuperado de http://www.uftm.edu.br/historico.

UFTM. Universidade Federal do Triângulo Mineiro. (2012). Análise do Plano REUNI da Universidade Federal do Triângulo Mineiro (2008-1012) e subsídios para a proposta de repactuação. Recuperado de http://pt.slideshare.net/comissaodiscenteuft m/anlise-plano-reuni-uftm-2008-a2012verso-final11.

Volanin, L. (2016). Poder e mídia: a criminalização dos movimentos sociais no Brasil nas últimas décadas. Recuperado de http://www.diaadiaeducacao.pr.gov.br/port als/pde/arquivos/760-4.pdf. 


\section{Dados sobre o autor:}

- Rafael De Tilio: Graduação (2002) e Pós-graduação (Mestrado/2005; Doutorado/2009) em Ciências, na área de Psicologia, pela USP. Desenvolve pesquisas referentes à área de violência, sexualidade, gênero e ideologia. É líder do HUBRIS/Laboratório de Estudos e Pesquisa em Sexualidade e Violência de Gênero e coordenador da LIS/UFTM - Liga de Sexualidade. Atualmente é Professor no Curso de Graduação e no Programa de Pós-graduação em Psicologia da UFTM

\section{Agradecimentos:}

Agradeço à Roberta Nunino Ribeiro pelo auxílio na fase de coleta de dados (realização das fotografias e organização do arquivo online das imagens). 